TITLE:

AUTHOR(S):

KERRY L, BURNS

THREE-TIME!ISIONAL MDDELLING A:ID GEOTI IERMAL PROCESS SIMULATION

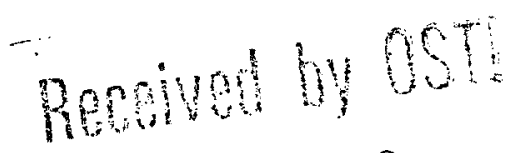

NOV 051990

SUBMITTED TO:

\author{
ThreE-Dimensional COMPITER GRAPHics in \\ MODELING GEOLOGIC STRUCTURES AND \\ SimULATING GEOLOFIC ?ROCESSES \\ October 7-1], 1990, FreibIIRG I. Br., Mest Germany \\ SPONSORED BY \\ GEOLOGICAL INSTITUTE OF THE UNIVERSITY OF FREIBURG \\ AMERI can ÁsSOCiation of PETROLEUM GEOLOgists \\ UR:ESCO (COGEODATA) \\ DEUTSCHE FORSCHUNGSGEMEINSCHAFT \\ INTERNATIONAL ASSOCIATION FOR MATHEMATICAL TEOLOGY \\ SOCiety of ECONOMIC Paleontolorists and Mineralorists

\section{PUBLISHED BY \\ (PFlug, Harbaugh, Merriam, eds.)} \\ PERGAMON PRESS, LONDON
}

By acceptance of this article, the publisher recognizes that the U.S. Government retains a nonexclusive. royalty-free license to publish or reproduce

the published form of this contribution, or to allow others to do so, for U.S. Government purposes. 


\section{DISCLAIMER}

This report was prepared as an account of work sponsored by an agency of the United States Government. Neither the United States Government nor any agency Thereof, nor any of their employees, makes any warranty, express or implied, or assumes any legal liability or responsibility for the accuracy, completeness, or usefulness of any information, apparatus, product, or process disclosed, or represents that its use would not infringe privately owned rights. Reference herein to any specific commercial product, process, or service by trade name, trademark, manufacturer, or otherwise does not necessarily constitute or imply its endorsement, recommendation, or favoring by the United States Government or any agency thereof. The views and opinions of authors expressed herein do not necessarily state or reflect those of the United States Government or any agency thereof. 


\section{DISCLAIMER}

Portions of this document may be illegible in electronic image products. Images are produced from the best available original document. 


\title{
THREE-DIMENSIONAL MODELLING AND GEOTHERMAL PROCESS SIMULATION
}

\author{
Kerry L. Burns \\ Division of Earth \& Environmental Sciences, \\ Los Alamos National Laboratory, \\ Los Alamos N.M. 87545 U.S.A.
}

\begin{abstract}
The subsurface geological model or 3-D GIS is constructed from three kinds of objects, which are a lithotope (in boundary representation), a number of fault systems, and volumetric textures (vector fields). The chief task of the model is to yield an estimate of the conductance tensors (fluid permeability and thermal conductivity) throughout an array of voxels. This is input as material properties to a FEHM numerical physical process model.

The main task of the FEHM process model is to distinguish regions of convective from regions of conductive heat flow, and to estimate the fluid phase, pressure and flow paths. The temperature, geochemical, and seismic data provide the physical constraints on the process.

The conductance tensors in the Franciscan Complex are to be derived by the addition of two components. The isotropic component is a stochastic spatial variable due to disruption of lithologies in melange. The deviatoric component is deterministic, due to smoothness and continuity in the textural vector fields. This decomposition probably also applies to the engineering hydrogeological properties of shallow terrestrial fluvial systems. However there are differences in quantity. The isotropic component is much more variable in the Franciscan, to the point where volumetric averages are misleading, and it may be necessary to select that component from several, discrete possible states. The deviatoric component is interpolated using a textural vector field. The Franciscan field is much more complicated, and contains internal singularities.
\end{abstract}

\section{KEYWORDS}

3D GIS, geological information system, subsurface geology, geophysics, FEHM, Finite Element Heat and Mass Flow, lithotope, textural vector fields, geothermal regimes, conductance tensors.

\section{EXPLORATION FOR GEOTHERMAL RESOURCES}

\section{Northern California Geothermal Province}

Exploration for geothermal resources is costly, due to the lack of surface expression of deep-seated physical processes, and the high costs of deep exploratory drilling. One method of optimizing exploration costs is to obtain maximum information from exploration data, and one promising method is to construct a numerical model of the geothermal regimes. 
properties, physical boundary conditions, and phase of migrating fluids, followed by trial and error adjustment to fit those conditions.

A large geothermal anomaly occurs in northern California, marked by a cluster of hot springs (Fig. 1). At the center of the cluster is the Geysers steamfield, the world's largest geothermal power producer, with a nameplate capacity of about $1800 \mathrm{MW}(\mathrm{e})$.

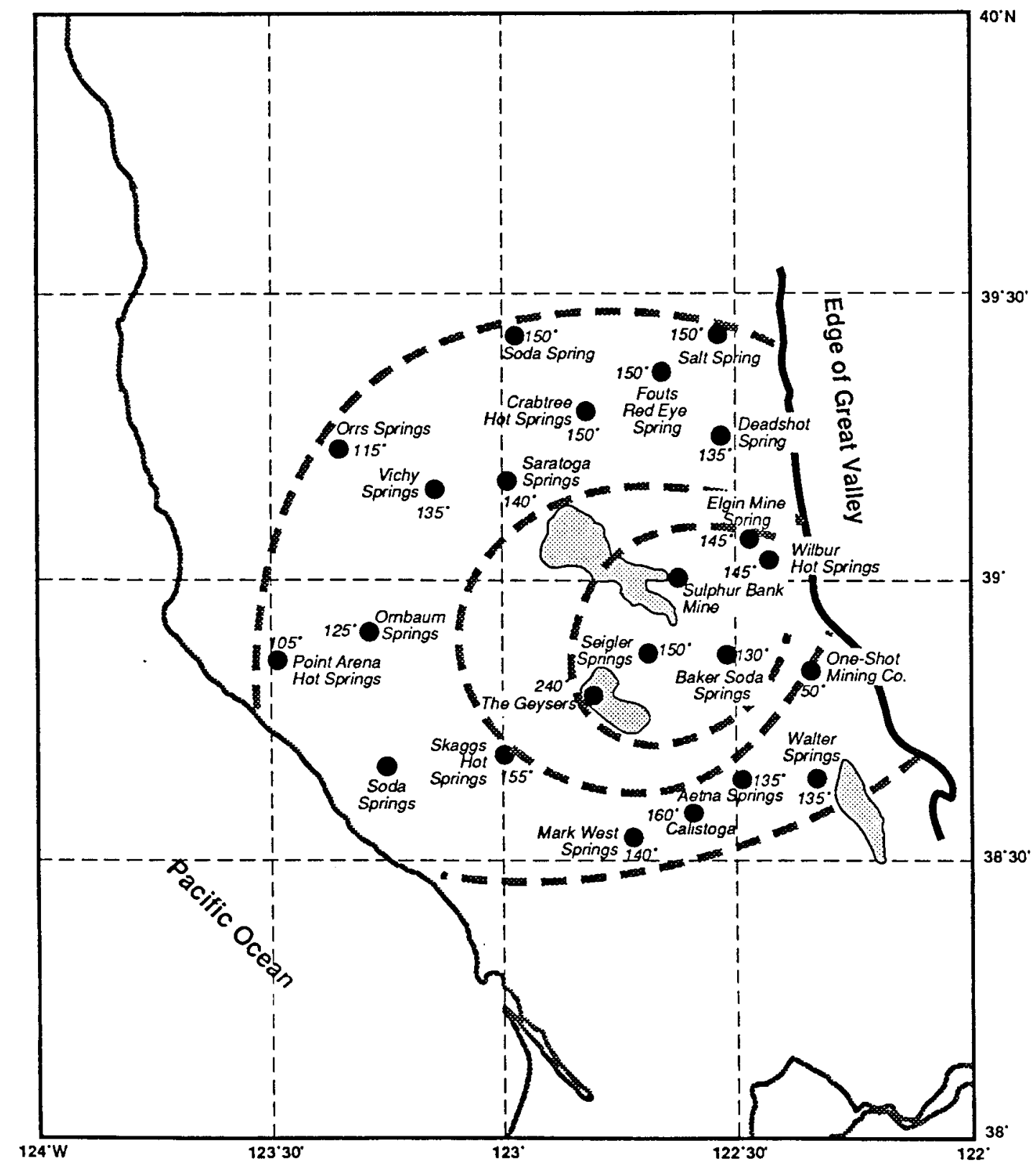

Fig. 1: The geothermal anomaly in northern California, showing the cluster of hot springs (filled dots), steamfield at the Geysers (shaded), and approximate temperature contours at a depth of $1.5 \mathrm{~km}$.

\section{Inhomogeneous Geothermal Regimes}

Geothermal resources are heterogeneous. Hydrothermal regimes include steamfields, hot springs and hot water aquifers, in which heat is carried mainly by convection in fluids. Petrothermal regimes, in which heat is carried mainly by conduction in rock, are the potential Hot Dry Rock resources. The framework stresses and pore pressure differ within the four regimes, so different production methods are required in each. The most important result of the numerical modelling for resource assessment is the determination, from place to place, of first, the sources of heat and fluids; second, the method of heat transport (convection or conduction); and third, the relative stresses and pressures. The FEHM (Finite Element Heat and Mass flow) model, developed by George Zyvoloski on the supercomputers at Los Alamos National Laboratory, will be used for the physical model. 
A linear belt of high heat flow extends from the Geysers steamfield (bottom left of Fig. 2) to Clearlake (top right), as shown by the location of deep exploratory wells. The subsurface geological, geophysical and geochemical information is assembled, by interpolation and extrapolation, onto a cross-section along the line BB. This has two dimensions in space $(L)$, none in time $(T)$, so the dimensionality is $L 2 T O$. The FEHM model is constructed as a slice through the crust, along the section line BB, with a thickness of $1 \mathrm{~km}$ (front slice of Fig. 3). This has dimensionality $L^{3} T 0$. Current conditions along this transect can then be modelled.

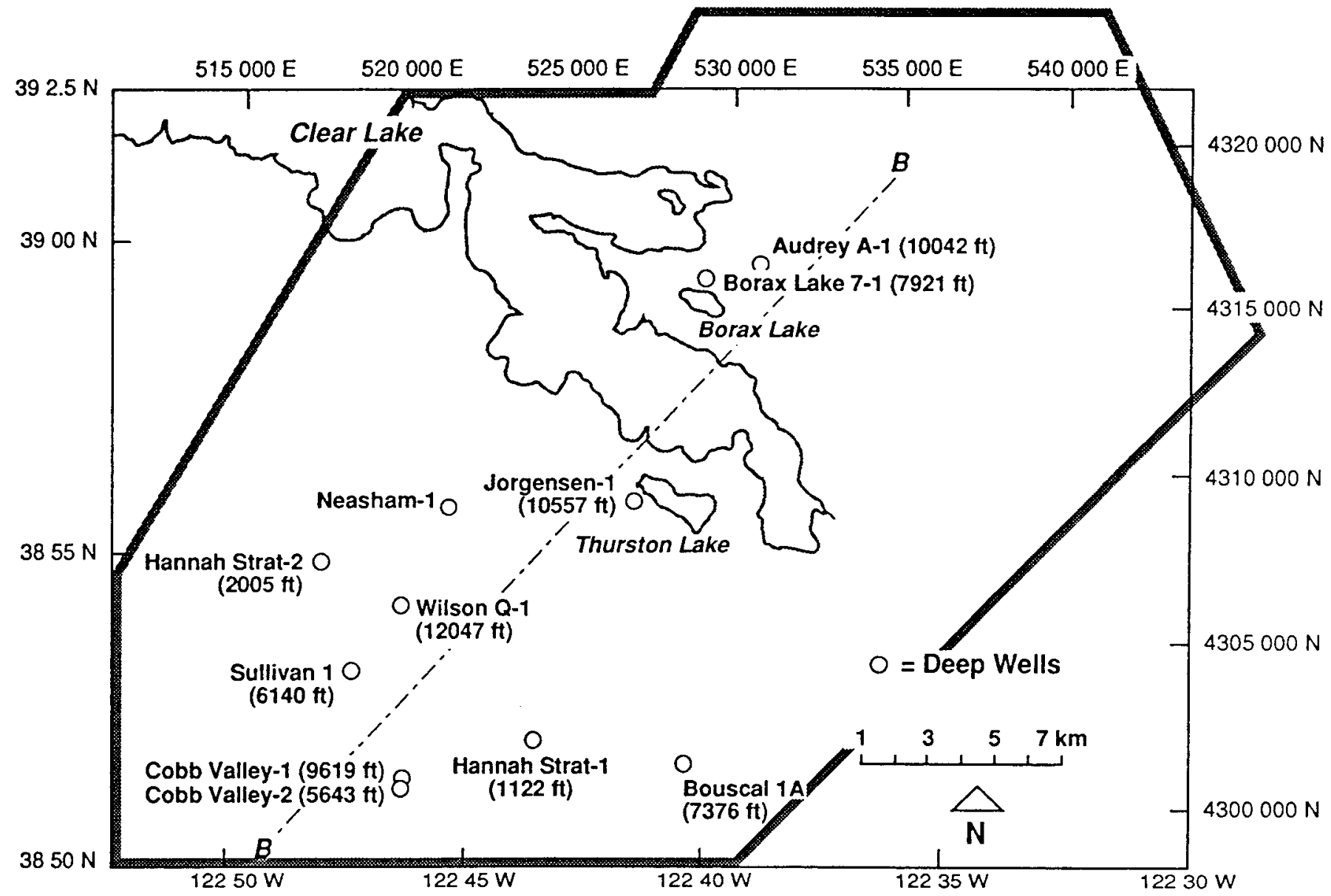

Fig. 2: Map of the central part of the geothermal anomaly, showing deep exploration wells (open dots) and the line of transect $\mathrm{BB}$.

However the region is volcanically active, and the geology of the subsurface is changing, with most of the volcanic field being less than one million years old, and the youngest volcanic cones being less than 100,000 years old. The heat source is probably a magma chamber at a depth of $6 \mathrm{~km}$, and the heat flow from this would take about one million years to stabilize by conduction. So the present heat flow probably contains transients. If we estimate the subsurface geology along the section line BB, backwards in time for about one million years, we create a dynamic picture of the subsurface geology, of dimensionality $L 2 T I$ (multiple slices of Fig. 3). If the FEHM model can be adjusted to take these transient heat sources into account, we will have a succession of $L^{3} T^{0}$ models representing an $L^{3} T^{1}$ process.

In comparison, a crustal transect was developed for the Atlantic coastal margin by Unger et al. (1989). This contained only subsurface geological information, and did not address any active physical process. Another transect has been proposed, from Death Valley to Yucca Flat (Borns et al., 1990), which proposes to take into account coupled geologic, tectonic, hydrologic, and thermal processes. However the physical processes are to be determined by deduction from observations, and no synthesizing physical model is proposed. The Geysers - Clearlake transect is unique in that the field data from numerous sources will be unified by incorporation into an FEHM model capable of treating multiple, coupled physical processes. 


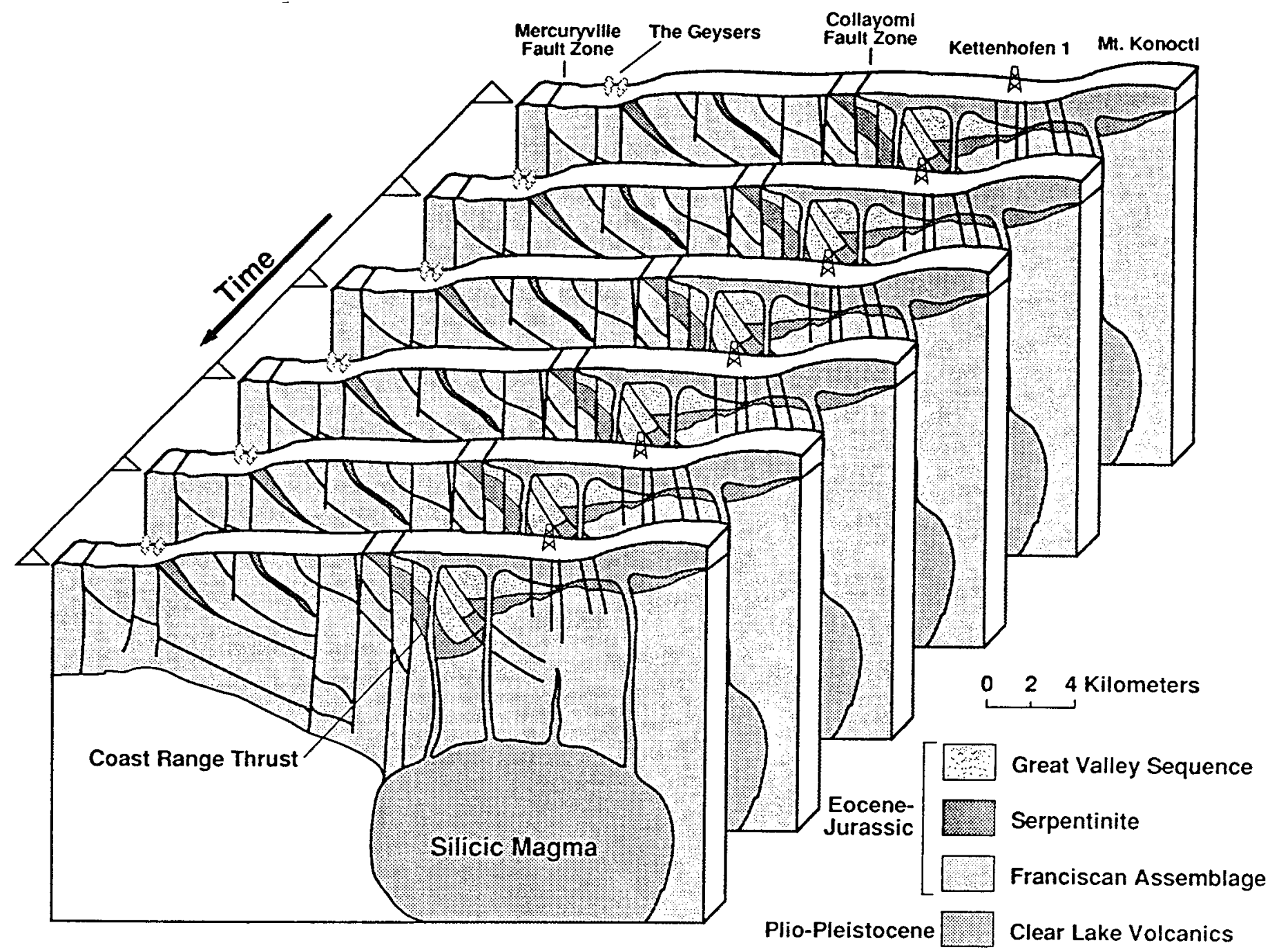

Fig. 3: Schematic diagram of the transect model. Each slice in this diagram is about $30 \mathrm{~km}$ in length (along the section line BB of Fig. 2), about $17 \mathrm{~km}$ in depth, and $1 \mathrm{~km}$ in thickness. The front slice is the youngest, getting progressively older behind.

OVERVIEW OF THE EXPLORATION MODEL

\section{Material Properties}

The most important material properties are conductivity and permeability, and in order to predict their distribution in the subsurface, it is necessary to formulate a geometric model of the subsurface geologic structure. This model comprises three different geometric component systems, which are respectively, a lithotope, internal textural vector field, and several fault systems. These three components are illustrated for Franciscan melange in Figs. 4, 5 and 6. They are listed briefly below, and described more fully later on.

Lithotope. This is a boundary representation of the unique subdivision of the rock into lithogenetic polyhedra, as defined by Burns (1988). Each polyhedron is an instance of a lithogenetic rock unit, or "rock formation". Subsurface geophysical information, from gravity, magnetics, reflection seismology, earthquake tomography, and resistivity, is incorporated into the construct.

Textural Vector Fields. The Cretaceous Great Valley Sequence is a wellbedded, stratiform sequence. The lithogenetic polyhedra are tabular in shape, with quasi-parallel top and bottom formation contacts. Internal lithological contacts are simple tabular sheets interpolated between formation boundaries.

The underlying Jurassic Franciscan Complex is a melange in which the lithological contacts have been destroyed by deformation. The orientation of the lithological contacts and accompanying foliations may be represented by a vector field normal to the contacts. 


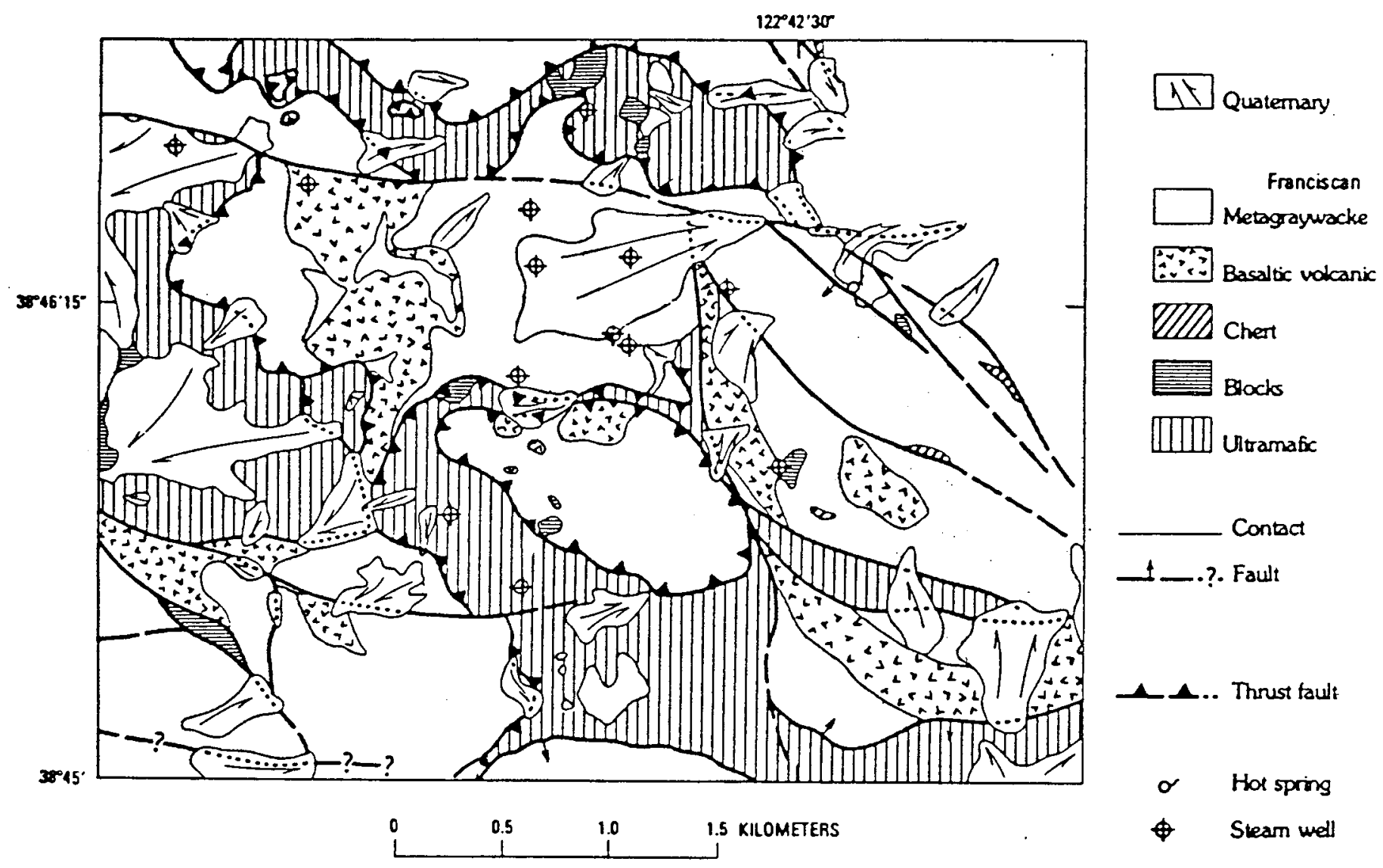

Fig. 4: Map of the Castle Rock Springs area, showing lithologic boundaries in the Franciscan assemblage. The three types of quasihorizontal contacts are ordinary stratigraphic, melange, and thrust faults.

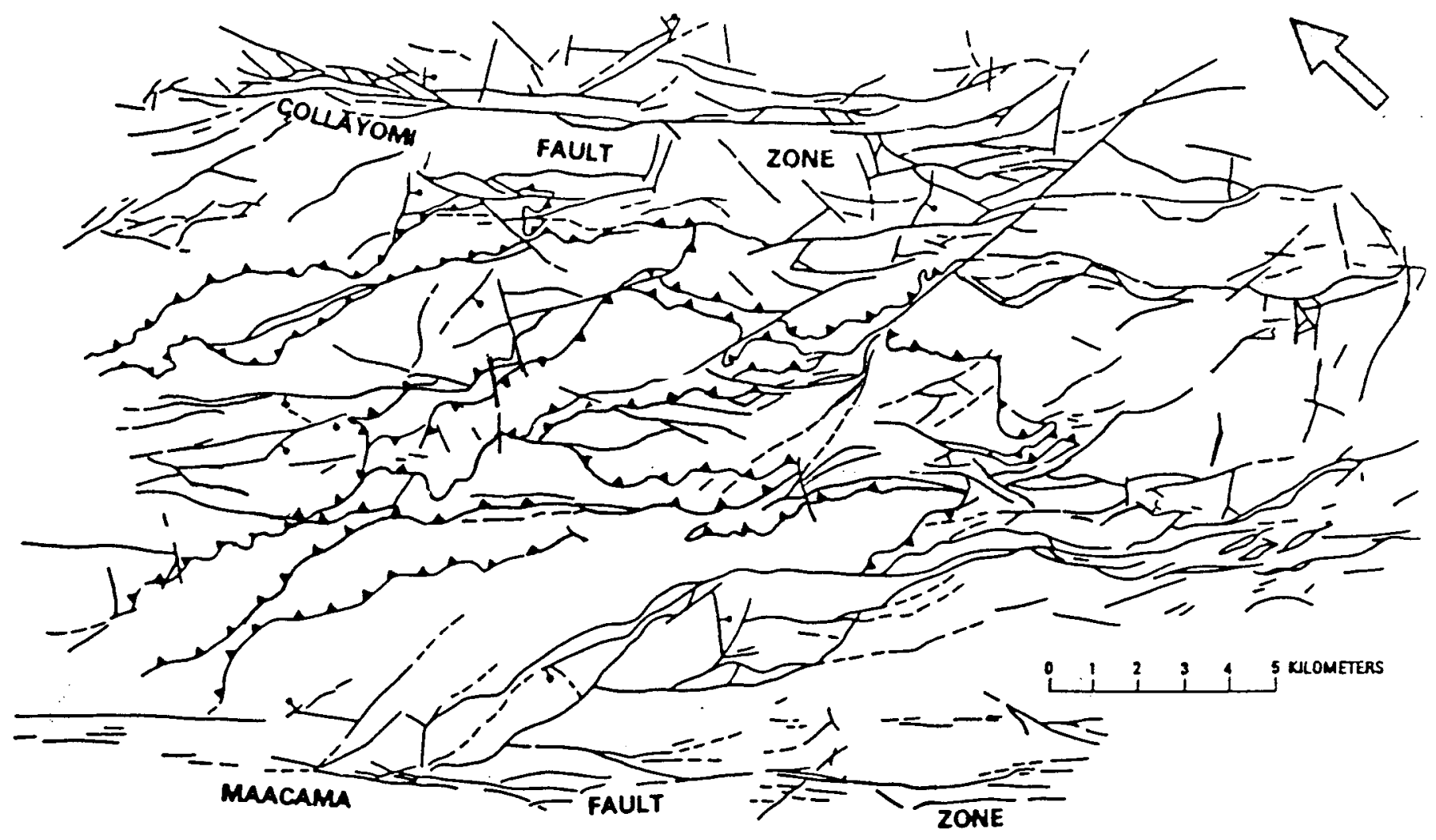

Fig. 5: Faults in the Geysers steamfield. There are two major systems, which are thrusts, and strike-slip faults of San Andrean affinity. 


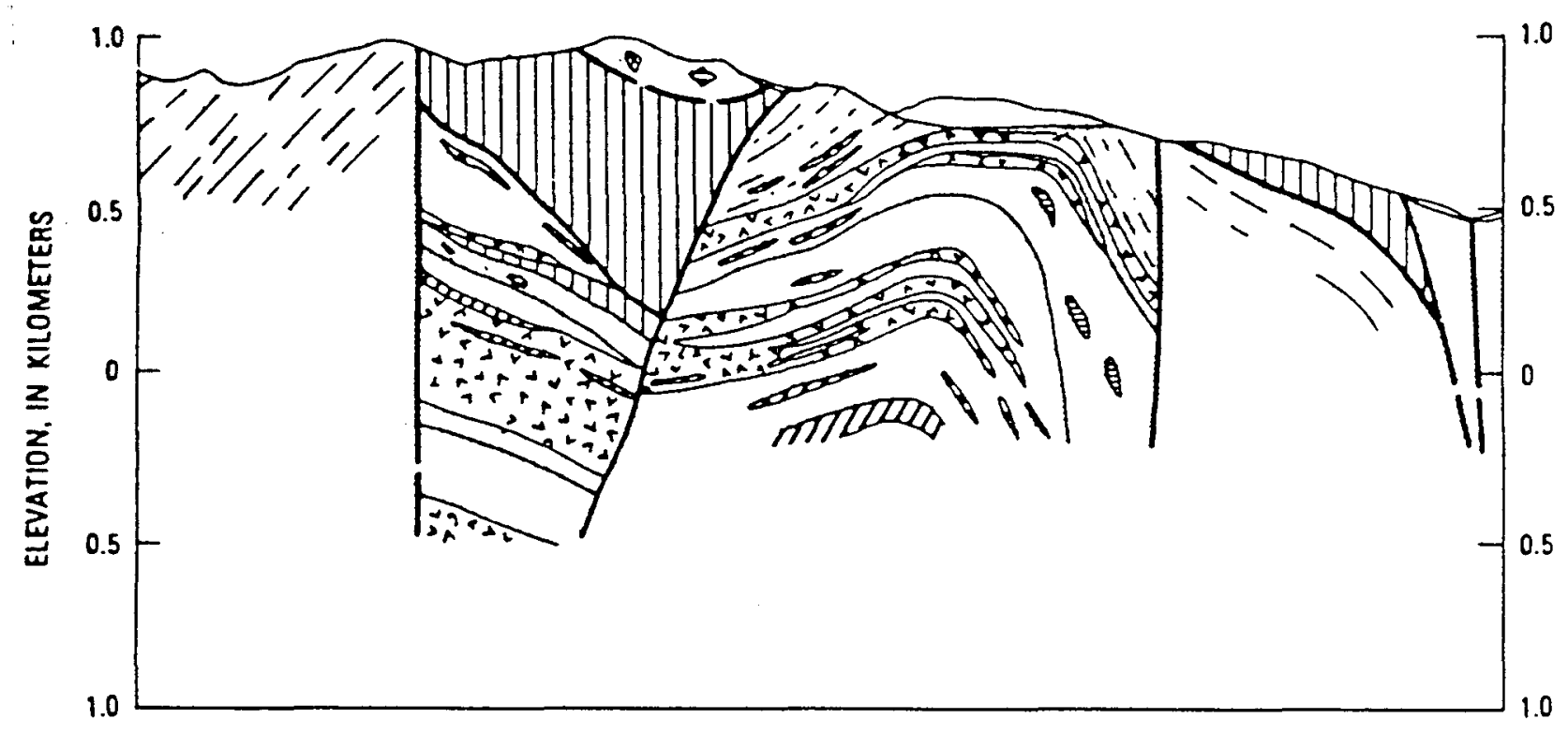

Fig. 6: SSW-NNE section of Fig. 4, showing the internal texture in Franciscan melange indicated by lithological lenses in the greywacke.

Fault Systems. According to Wagner \& Bortugno (1982), the thrust faults include disconnected fragments of the CBT (coastal belt thrust) and CRT (Coast Range thrust). There are also younger reverse faults, and yet younger strike-slip faults related to the San Andreas system. The latter are so young that they have been dated from their geomorphic expression (Bortugno, 1982).

In the post-Jurassic rocks, the mean values of conductivity and permeability are determined simply by the lithology inside each polyhedron. In the Franciscan melange, the lithology is not a deterministic, but a stochastic quantity. There is a defined probability of encountering lithologies such as metagreywacke, chert or greenstone, at any point. The mean values of material physical properties are replaced by a discrete set of probable values (Einstein \& Baecher, 1981, 1983).

Material anisotropy is governed by the internal textures. The most important is that formed by small-scale lithological contacts. It is represented by a vector field normal to the contacts. The second-order properties of the conductance and permeability are axially-symmetric about the field vector.

\section{Boundary Conditions}

Temperature. Temperatures are obtained from two sets of wells. The first are deep exploration holes (Fig. 2), where the temperature was measured during drilling (mud outflows, or bottom-hole) and in subsequent logs. The logs vary from run to run, depending upon thermal effects caused by drilling, and determining the true temperatures in deep holes is a non-trivial problem in interpretation of thermal transients around wellbores. The second are patterns of shallow "gradient" holes, where the temperature is obtained from logs. The mean surface temperature of slopes with average solar aspect is about 12 deg.C. These temperature measurements specify a boundary condition on the upper surface of the FEHM model. The lower boundary condition is set at the top of the inferred magma chamber, at the inferred melting temperature; and at the edges of recent necks and dykes, at inferred cooling temperatures.

Geochemistry. Stable isotope and tritium data will be analysed to determine whether the thermal waters originated from large interconnected reservoirs or from small, isolated, fault-controlled systems of small volume. Stable isotope data will indicate recharge areas and reservoir processes, while tritium data will determine mean residence time and reservoir volume.

The thermal fluids, sampled in hot springs and wells, are usually (>90\%) meteoric in this region, with some connate water, expelled from the unmetamorphosed (metamorphosing!) Cretaceous Great Valley Sequence. Magmatic water is difficult to find. Stable-isotope geochemistry can fingerprint the water source as meteoric, connate or magmatic; and indicate whether the fluid was transported as liquid or vapour. The isotopic composition of water can indicate source temperature. Tritium in water geochemistry can determine, with fairly large uncertainties, the size of any pools (reservoirs) along the flow path; and determine residence time in the reservoir. 
under the regional geothermal anomaly, appear to be confined to cold crust overlying magmatic rocks at depths shallower than $6 \mathrm{~km}$. The location of the magmatic earthquakes is probably controlled by a combination of temperature (induced contraction stress) and fluid pressure, and probably indicates the proximity of sources of pressurized hot fluid.

Analysis of first motions of the earthquakes indicates stress conditions at the source. Inversion of the first motion data will provide estimates of in-situ stress (Bufe et al, 1981). This will help determine which faults are likely to be conductive under the current stress regime.

\section{Heat-Mass Transport Processes (FEHM Model)}

The synthesizing numerical physical model is described by Zyvoloski et al (1988). The flow of fluids through the crust is modelled using the equations of mass balance for the fluid phases, energy balance in the fluid-solid system, and Darcy's flux law for each fluid phase (liquid and vapour), in conjunction with the equations of state for the fluids. Solid deformation is modelled using static stress balance. The effect of fluid pressure on the rock is treated by poroelastic theory with an effective stress law. Thermal effects in the rock are modelled by first order thermoelasticity.

The equations of mass and energy balance are strongly coupled because porosity and permeability vary with displacement, rock moduli vary with pressure, and pore pressure affects displacement in the solid. The energy balance and solid deformation are strongly coupled through thermal deformation, temperaturedependent rock moduli and frictional heating. The resulting equations are nonlinear, coupled, partial differential equations.

\section{Geothermal Regimes}

The concept of geothermal regime was explained by Muffler et al (1979). A pre-computer interpretation of the geothermal regime at the Geysers is shown in Fig. 7. The material is assigned to one of three permeability classes, which are impermeable (serpentinite, greenstone, melange and meta-greywacke); fracture- dominated permeability (greywacke); and matrix- dominated permeability (young acid volcanics). The fluid phase is predominantly vapour at the Geysers, liquid elsewhere. The FEHM model aims to sharpen, refine, and extend this interpretation.

The geological and geophysical data will provide the material properties for the FEHM model. The temperature, geochemical, and seismic data will provide boundary conditions and interior constraints. The data is then transformed to SOE (spatial occupancy enumeration) form, for transfer to the FEHM program. The resolution (unit voxel) is $1 \mathrm{~km}$ per side.

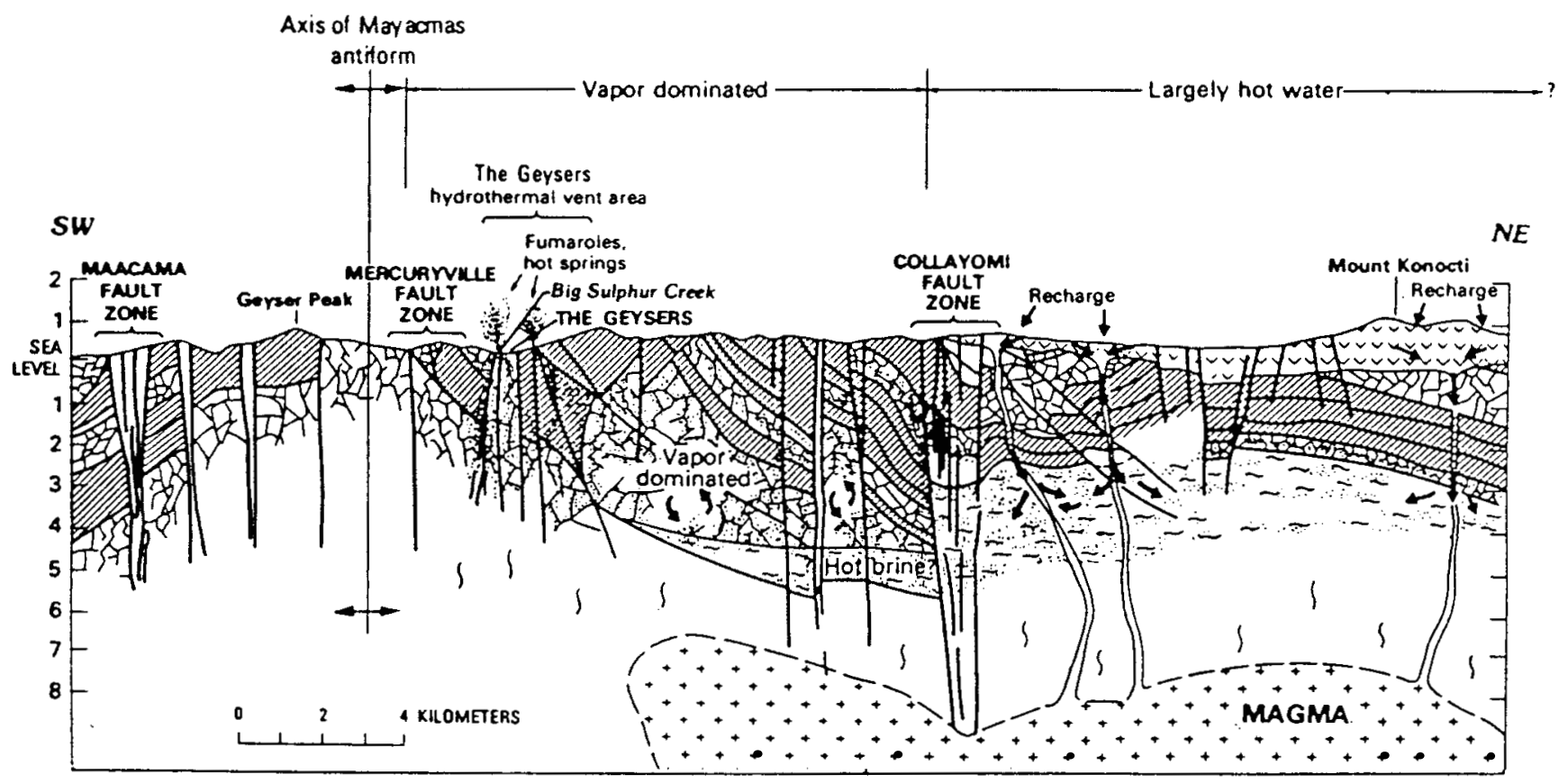

Fig. 7: Diagram of the geothermal regime at the Geysers. 
The FEHM model will then be adjusted to fit the data. It is expected to delineate different regions as steamfields, hot springs, hot water aquifers and regions of hot dry rock, and yield quantitative information on each resource. The result will be guidance on which production method should be used for energyextraction in each region, and the size and location of the resource accessible by different engineering methods.

We now examine some of the preceding topics in detail.

\section{THREE DIMENSIONAL LITHOTOPE}

\section{Topology of the Geological Subsurface}

The topology of the three-dimensional subsurface was shown by Burns (1988) to be readily generalized from the two-dimensional topology that has become familiar in digital mapping. The following description follows that treatment. A subsurface "cell" or unit occurrence of a rock formation is a lithogeneticallyhomogeneous volume in the subsurface. This is bounded by "faces" which are interfaces with adjoining cells. A face is a surface patch which is defined by continuity of curvature. Each face has a perimeter ring of "edges" which are space curves, and each edge is bounded by a pair of "vertices". The subsurface is then a construction based on geometrical entities of dimensionality 3,2,1 and 0 , which are cells, faces, edges and vertices, as shown in Fig. 8(a). The symbols C3, F3, E3, and V3, will be used to denote these objects.

These objects are related to each other by adjacency relations. In a valid model, two adjacent edges are incident on a face, and two adjacent faces on an edge, and three edges on a vertex. After Coxeter (1973, p.68), use $n(A, B)$ to denote the number of B-objects that are incident upon a single A-object. Then $n(F 3$, $\mathrm{C} 3)=2, \mathrm{n}(\mathrm{E} 3, \mathrm{~F} 3)=2$, and $\mathrm{n}(\mathrm{V} 3, \mathrm{~F} 3)=3$. These validity conditions are not the same for all threedimensional constructs (Requicha, 1980; Weiler, 1985). These conditions are based upon geological considerations. Adjustment of a preliminary three-dimensional construct to meet these conditions is termed "reduction to normal form", defined below.

If the three-dimensional space is intersected with a surface, $\mathrm{X} 2$, which may be plane or curved, the result is a two-dimensional diagram, such as a cross-section, subcrop map or underground plan. Where $x$ denotes geometric intersection, define a lithological "domain" by $\mathrm{C} 2=\mathrm{C} 3 \times \mathrm{X} 2$, "boundary" by $F 2=\mathrm{F} 3 \times \mathrm{X} 2$, and "junction" by $\mathrm{E} 2=\mathrm{E} 3 \times \mathrm{X} 2$. The cross-section is then a two-dimensional construct of domains, boundaries, and junctions, as shown in Fig. 8(b). If X2 is the interface between the subsurface and atmosphere, the construct is an ordinary geological map, or outcrop map, otherwise, a subcrop map.

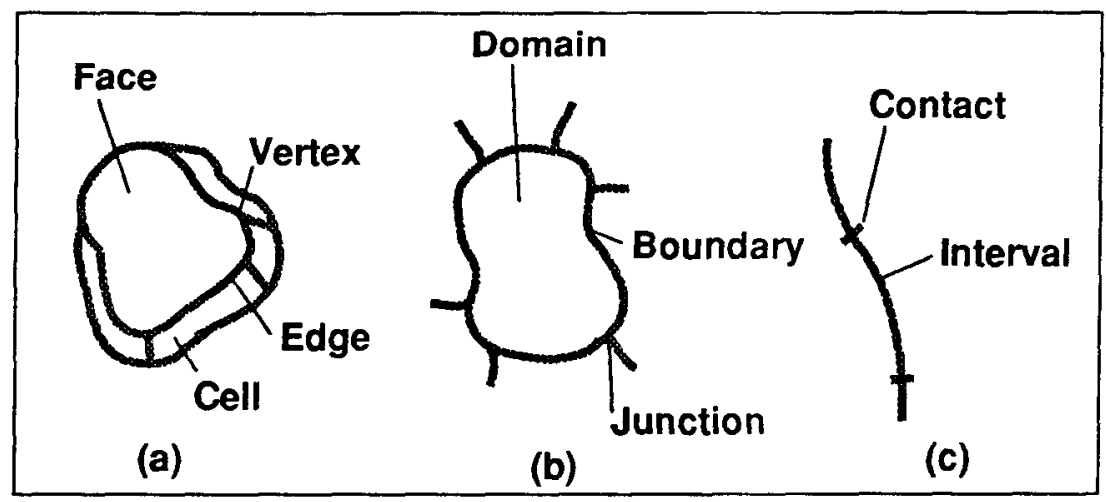

Fig. 8: Lithogenetic units in a polytope: (a) cell in three dimensions, (b) domain in two dimensions, and (c) interval in one dimension.

If the three-dimensional space is intersected with a line, Y1, which may be plane or curved, the result is a one-dimensional diagram, such as a welllog, traverse line or highway log. Define a lithological "interval" by $\mathrm{C} 1=\mathrm{C} 3 \times \mathrm{Y} 1$, and "contact" by $\mathrm{F} 1=\mathrm{F} 3 \times \mathrm{Y} 1$. The subsurface log is then a one-dimensional construct of intervals and contacts, denoted $\mathrm{C} 1$ and F1, as shown in Fig. 8(c).

The geometric objects in a 3D lithotope are summarized in Table 1. In a space of dimension d, the extensive lithological unit is $\mathrm{Cd}$, which is a cell, domain, or interval. Two adjacent lithological units share 
an object Fd which is an interface. Two of these share an object Ed which is an edge or junction. And if $d$ is three, three of these are incident on an object Vd which is a vertex.

\begin{tabular}{|c|c|c|c|c|}
\hline \multirow{2}{*}{$\begin{array}{l}\text { Dimension } \\
\text { of Space }\end{array}$} & \multicolumn{4}{|c|}{ Dimension of Object } \\
\hline & 3 & 2 & 1 & 0 \\
\hline $\begin{array}{r}3 \\
\text { subsurface }\end{array}$ & $\begin{array}{l}\text { C3 } \\
\text { cell }\end{array}$ & $\begin{array}{c}\text { F3 } \\
\text { face }\end{array}$ & $\begin{array}{l}\text { E3 } \\
\text { edge }\end{array}$ & $\begin{array}{c}\text { V3 } \\
\text { vertex }\end{array}$ \\
\hline map, section & & $\begin{array}{c}\mathrm{C} 2 \\
\text { domain }\end{array}$ & $\begin{array}{c}\mathrm{F} 2 \\
\text { boundary }\end{array}$ & $\begin{array}{c}E 2 \\
\text { junction }\end{array}$ \\
\hline log, traverse & & & \begin{tabular}{|c|c} 
C1 \\
interval
\end{tabular} & $\begin{array}{c}\mathrm{F} 1 \\
\text { contact }\end{array}$ \\
\hline index, key & & & & $\begin{array}{c}\text { Co } \\
\text { lithology, } \\
\text { transition }\end{array}$ \\
\hline
\end{tabular}

Table 1: Tabulation of geometric objects in a lithotope.

\section{Indexation}

Bouille (1976) typed objects on a map by a subscript index set. A systematic indexation scheme helps to ensure a valid assembly. Bouille's scheme is readily extended to three dimensions. The index set $(i, j, \ldots, 1)$ refers to constituent rock formations. An object of any particular type may be repeated many times. An individual is distinguished by an additional index, which counts the occurrences.

For example, on a map, $\mathrm{C} 2 \mathrm{im}$ is the mth outcrop of the ith lithology. The set $\mathrm{C} 2 \mathrm{i}=\{\mathrm{C} 2 \mathrm{im}: \mathrm{m}=1, \mathrm{M} 2\}$ is a "rock formation" which occurs in M2 outcrops. It is convenient to put the formations in order. If formation $\mathrm{C} 2 \mathrm{i}$ is older than formation $\mathrm{C} 2 \mathrm{j}$, assign the indices so that $\mathrm{i}<\mathrm{j}$. Then the notation F2ijp means that $F 2 \mathrm{ijp}=(\mathrm{C} 2 \mathrm{im}$ o $\mathrm{C} 2 \mathrm{jn})$ is the pth occurrence of an interface between adjacent outcrops of formation $\mathrm{C} 2 \mathrm{i}$ and $\mathrm{Crj}$, where the contact relationship is denoted "o".

\section{Operations and Transformations}

There are operators which, applied to a construct, alter its form. These include normalization and triangularization.

Normalization. A map is in Kempe-normal form (Appel \& Haken, 1977) when no domain completely surrounds another and no more than three domains meet at a point. Intrusive plugs on geological maps sometimes have an isolated boundary. This can be linked to other boundaries on the map by introducing a "virtual" boundary (Bouille, 1976). A set of editing operations like this, which converts the field map to normal form, is termed "normalization", $\mathbf{N}$. The inverse operation, N', is striking virtual boundaries.

Triangularization. This is the pair of operations that transform a Kempe-normal construct to another form, termed the dual. This is the reciprocation operation of Coxeter (1973, p.17).

\section{Graph of the Cartographic Form}

Bouille (1976) recognized three graphs in two dimensions. These were termed the "cartographic form", "spatial succession" and "process model" by Burns (1988). The graph of interest here is the "cartographic form", $S$, where $S=\langle$ arc, node $\rangle=\langle F 2, E 2\rangle$.

The cartographic form is $S=<\operatorname{arc}$, node $>=\langle\mathrm{E} 3, \mathrm{~V} 3\rangle,<\mathrm{F} 2, \mathrm{E} 2\rangle,<\mathrm{C} 1, \mathrm{~F} 1\rangle$ or $<0, \mathrm{C} 0\rangle$ for spaces of dimension $3,2,1$, or 0 , respectively, which run down the last two columns of Table 2 . For example, the well- $\log$ form is a lineal thread $S=\langle\mathrm{Cl}, \mathrm{F} 1\rangle=<$ lithological intervals, contacts $\rangle$. The degenerate form $S=$ $<0, \mathrm{CO}\rangle$ has no arcs, and is the set of nodes which are lithological transitions, where transition at a unit means the change from the formation below the unit to the formation above the unit. In two dimensions, this is the format of the Bureau of Census topologically structured "Tiger" files (Herring, 1987), while in three dimensions, it is a wireframe model. 


\begin{tabular}{|c|c|c|c|}
\hline \multirow{2}{*}{$\begin{array}{l}\text { Dimension } \\
\text { of Space }\end{array}$} & \multicolumn{3}{|c|}{ Dimension of Object } \\
\hline & 3 & 2 & 1 \\
\hline $\begin{array}{r}3 \\
\text { subsurface }\end{array}$ & $\begin{array}{l}\mathrm{C3} \\
\text { cell }\end{array}$ & $\begin{array}{c}\mathrm{F} 3 \\
\text { face }\end{array}$ & $\begin{array}{c}<E 3, V 3> \\
<e d g e, \text { vertex }\end{array}$ \\
\hline map, section & & $\begin{array}{c}\mathrm{C} 2 \\
\text { domain }\end{array}$ & $\begin{array}{c}<\mathrm{F} 2, \mathrm{E} 2> \\
<\text { boundary, junction> }\end{array}$ \\
\hline log, traverse & & & $\begin{array}{c}<\mathrm{C} 1, \mathrm{~F} 1> \\
\text { <interval, contact> }\end{array}$ \\
\hline index, key & & & $\begin{array}{c}<\text { null, } \mathrm{CO}> \\
<\text { <no arcs, transitions }\end{array}$ \\
\hline
\end{tabular}

Table 2: Components of the graph of cartographic form, eg. $S=\langle$ arc, node $\rangle=\langle E 3, V 3\rangle$.

\section{Construction of the Lithotope}

In ordinary model construction, such as in CAD/CAM or digitization of geologic maps, the topology is completely known. The objects are known according to location and according to their topological character. So construction of a model is simply a matter of structuring the computer files. However the topology of a collection of geologic field data in 3D is not known, and has to be inferred from the data. This is a fundamental difference between construction of 2D and 3D models.

Each of the geometrical objects in the three-dimensional lithotope is constructed by inference from objects of lower dimensionality. This requires a search for objects of appropriate topology, which can be done by manual assignment if known, or by automatic search procedures. As an example of the latter, suppose the set of formations with indices $\{i, j, k, \ldots\}$ were observed at scattered points in space. For each point, calculate a list of the nearest neighbours. For the ath point, this will be an ordered set Ka drawn from the preceding set. If the first three indices of $\mathrm{K} a$ are all the same, the point is classified as in the interior of a cell. If the first two indices are different, the point is near a face; and if the first three are all different, the point is near a vertex. By searching through the data set in this manner, the topology can potentially be constructed.

The lithotope is, therefore, recovered from the data by topological inference from the lithology observed at the data points. The normal form is a consequence of a valid procedure.

\section{FAULT SYSTEMS}

\section{Topology of Fault Systems}

The proposed lithological search procedure will generate a faulted lithotope, that is, the surfaces will include faults as well as formation boundaries. The faults must be identified by field observations and distinguished as such in the construct.

\section{Thrust Systems}

The two thrust systems are widely exposed and recognized regionally. The surfaces are quasi-horizontal, offset by later faults. A method of reconstruction of discontinuous surfaces was described by Pouzet (1980), and similar techniques are available commercially.

\section{Strike-slip Systems}

The large offsets between the patches of thrust faults provides a measure of strike-slip displacements. The strike-slip systems are so young that the space curves can be found, traced by the fault surfaces on the topography (Bortugno, 1982). The appropriate description is edge-based (Weiler, 1985) or boundary loops (Bak \& Mill, 1989). There are few subsurface intersections in wellbores. The surfaces are probably nearvertical. 


\section{Vector Field Normal to Layered Textures}

The Cretaceous Great Valley Sequence is a wellbedded, stratiform sequence. Within each stratigraphic unit, a field of surfaces is formed by sedimentary laminae, bedding and minor lithologic contacts. The normal vectors to the surfaces constitute an orientation vector field, as described by Agterberg (1974, pp.488-508), and as illustrated in Fig. 9.

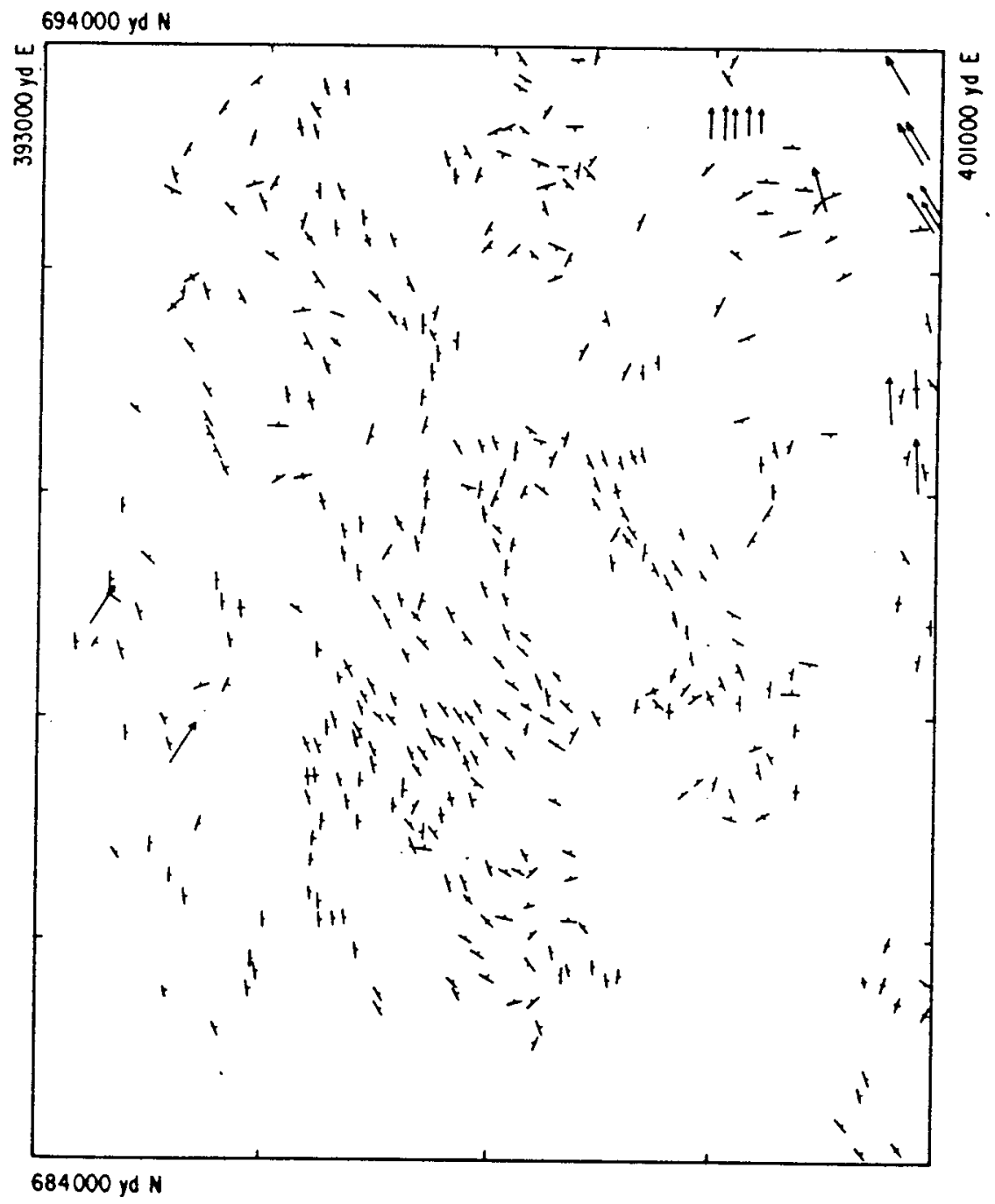

Fig. 9: Field of planar surfaces in a metamorphic terrain (Port Davey, Tasmania). The normals to these surfaces constitute a textural vector field.

The underlying Jurassic Franciscan Complex is a mixture of lithologies, such as greenstone, chert and greywacke, in the form of lenticular blocks. The complex is a melange in which the formation boundaries have been destroyed by deformation. Internal lithological contacts are of tectonic, not sedimentary or magmatic, origin. The lithologic contacts and accompanying foliations tend to form a layered texture, which may also be represented by a unit vector field normal to the surfaces.

\section{Topology of the Vector Fields}

The vector fields are reconstructed by extrapolation and interpolation. Interpolation methods were described by Agterberg (1974), Watson (1985) and Mendoza (1986). The fields are continuous within lithogenetic polyhedra. In fact, this is a criterion of "lithogenetic". The fields terminate on two opposite faces of the polyhedra. In sedimentary formations, these are the upper and lower faces. The tangent curves end in "attachment points" at the faces. The fields in adjacent polyhedra are different, that is, there is a discontinuity across faces. 
The vector field may also have singularities, or critical points, inside the polyhedra, as illustrated in Fig. 10 . These are axial surfaces of folds, traces of faults and mylonite zones, or zones of concentrated shear. The critical points are defined as points where tangent curves in the field start arbitrarily close to each other, but end up in substantially different regions.

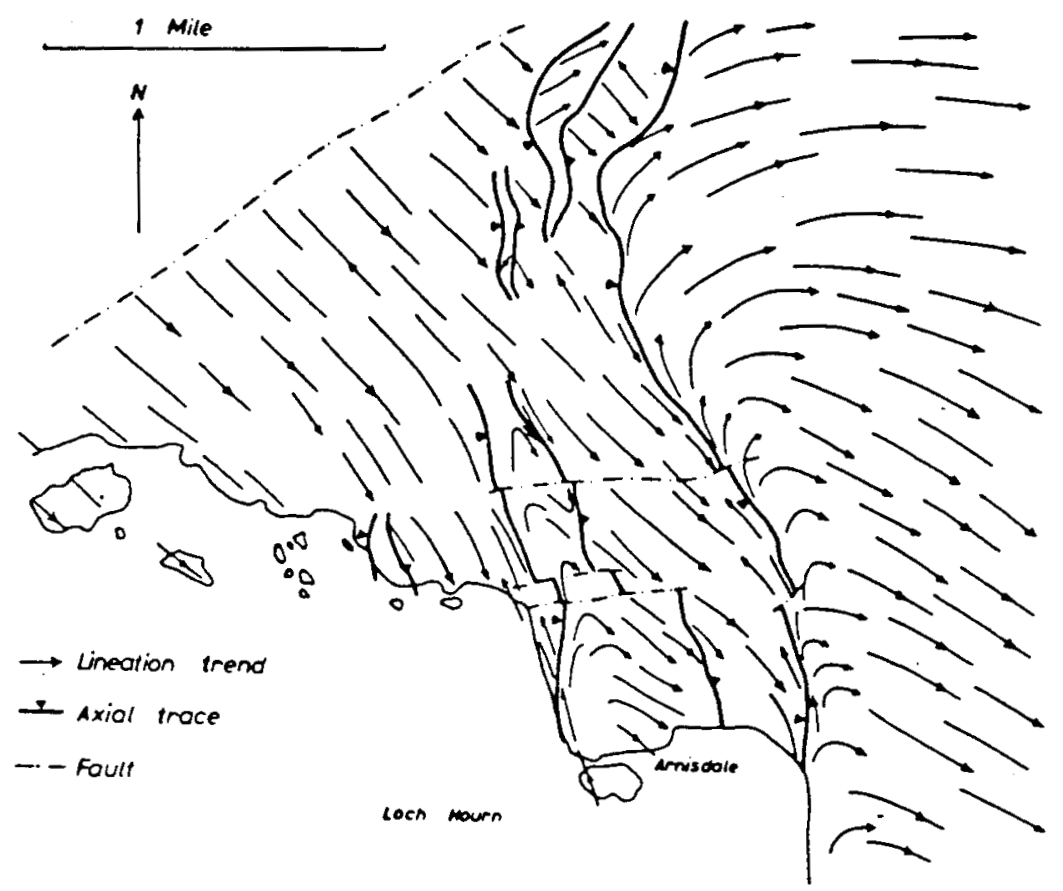

Fig. 10: Discontinuities in a textural vector field (Loch Hourn, Scotland).

\section{Topology of Fluid Flow Fields}

The representation of vector fields is at the frontier of scientific visualization. Helman and Hesselink $(1989,1990 \mathrm{a})$ have pioneered the visualization of the topology of vector fields of dimensionality $L^{2} T^{l}$. The parameter in the flow field is the fluid velocity.

The reconstruction of the flow field starts with the classification of points on the boundary (attachment and detachment points). Critical points are then found, as those points where the magnitude of the flow vector vanishes. The critical points are classified according to the eigenvalues of the Jacobian matrix of the vector, with respect to position, at the critical point. The eigenvalues classify a critical point as an attracting node, a repelling node, an attracting focus, a repelling focus, a centre, or a saddle.

The field is reconstructed by following tangent lines in the field, from where it leaves one critical or boundary point, to where it reaches another. Each tangent line is represented by a linked list in Common Lisp. The tangent curves are integrated in Fortran routines called from Lisp. The field is reconstructed in two dimensions for an instant of time. Reconstructions for a series of successive instances led to the $L 2 T I$ visualization of Helman \& Hesselink (1990b).

\section{INTERFACING THE 3D-GIS TO THE FEHM MODEL}

\section{Topology of SOE Form}

The subsurface geological model is transformed to SOE (spatial occupancy enumeration) form (Requicha, 1980), where each voxel is one cell of the FEHM model. Each cell is assigned a topology or character according to the predominant character in the geological model.

The topological character derived from the lithotope is whether the voxel is the interior of a polyhedron, or lies on a face, edge or vertex. The character derived from the fault systems is that the point lies on one of the fault systems or not. The character derived from the textural vector fields is whether the point lies on an attachment point, detachment surface, axial surface, or none of these. 
The conductance parameters are tensors, and can be treated as the sum of two parts, a deviation, or isotropic part, or mean value, and a "difference tensor", or deviatoric part (Jaeger, 1962, p.90). The isotropic part of the permeability and conductivity inside polyhedra, at no special points, is specified by scalar properties of the lithology, such as sand/shale ratio and grain size. The value is estimated from calibration data.

In the Franciscan melange, the lithology inside an ordinary voxel is usually unpredictable. It can, however, be assessed on a probabilistic basis, using methods such as those of Einstein \& Baecher $(1981,1983)$. The calibration data could be used to assign "most probable" conductances to voxels in the melange.

The permeability is, however, very heterogeneous, and is likely to be quite different at un-ordinary points. Low permeability zones are expected along faults of the strike-slip systems, possibly with an error-function distribution for several hundred metres either side of the fault surface.

This is a wrench-tectonic regime, and different generations of faults are likely to intersect in vertical lines. As a result, linear, low permeability zones are expected at fault intersections. The high areal frequency of hot springs (Fig. 1) may be attributed to this cause.

\section{Deviatoric Conductances}

To a good approximation, the deviatoric permeability tensor is axially symmetric, oblate, with the least principal axis normal to the layering, and the other two principal axes parallel to the surface. The ratio of the two extreme principal values is very high. The anisotropy is specified by the ratios of principal axes and the orientation of the normal to layering. So the textural vector field provides information on the orientation of the deviatoric conductance tensors at ordinary points in the vector field. The conductance tensors associated with singularities remain to be determined.

\section{Resource Assessment vs Site Characterization}

In engineering hydrogeology of shallow terrestrial fluvial systems, especially those associated with cleanup of toxic waste, the isotropic material properties are determined by a random spatial process, best treated by geostatistical methods (Turner, 1989). In this resource model of the Franciscan Complex, the variations are even greater. A volumetric average might not be valid, and it may be necessary to select a value from a discrete set of probable states.

The deviatoric components are a deterministic process in both cases. However the orientation is likely to be fairly constant in fluvial channels, while it is a complicated field containing singularities in the Franciscan. It is concluded that while there is fundamental similarity between this resource model at regional scale and site characterization at engineering scales, the resource model presents a higher level of complexity.

\section{ACKNOWLEDGEMENTS}

The author is grateful to Professors Herbert Einstein, Geoff Watson, Lambertus Hesselink, and James Helman, and to colleagues Drs. James Albright, Dave Duchane, Bob Potter, Fraser Goff, and George Zyvoloski, for helpful discussions. Ruth Bigio prepared some of the figures. Figures 4 to 7 are based on McLaughlin (1981, Fig. 9, p.18; Fig. 7, p.16; and Fig. 6, p.14). Figure 10 is based upon Agterberg (1974, Fig. 108, p.495), and is reproduced with permission of the author and Elsevier Scientific Publishing Company.

\section{REFERENCES}

Agterberg, F.P. (1974). Geomathematics. Elsevier, Amsterdam.

Appel, K., Haken, W. (1977). The Solution of the Four-Color-Map Problem. Scientific American, 237, 108121.

Bak, P.R.G., Mill, A.J.B. (1989). In: Three Dimensional Applications in Geographic Information Systems (J. Raper, ed.), pp. 155-182. Taylor \& Francis, London.

Borns, D.J., Sass, J.H., Schweickert, R.A. (1990). Proposed Study of the Basin and Range From Death Valley to Yucca Flat: EOS Trans. AGU, 71, 1012-1013. 
Bortugno, E.J. (1982). Map Showing Recency of Faulting, Santa Rosa Quadrangle, California, 1:250,000. Regional Geologic Map Series, California Division of Mines and Geology, Sacramento.

Bouille, F. (1976). Graph Theory and the Digitization of Geological Maps. J. Int. Assoc. Math. Geol., 8, 375-393.

Bufe, C.G., Marks, S.M., Lester, F.W., Ludwin, R.S., Stickney, M.C. (1981). In: Research in the GeysersClear Lake Geothermal Area, Northern California (R. J. McLaughlin, J. Donnelly-Nolan, eds.), Geol. Surv. Prof. Pap., 1141, pp. 129-137, US Govt. Printing Office, Washington.

Burns, K.L. (1988). Lithologic Topology and Structural Vector Fields Applied to Subsurface Prediction in Geology. Proc. GIS/LIS'88, 1, 26-34. ASPRS, Falls Church.

Burns, K.L., Potter, R.M. (1990). Application of Hot Dry Rock Technology in the Clearlake area, California. In: The National Energy Strategy -- The Role of Geothermal Technology Development, Department of Energy, Washington DC, in press.

Coxeter, H.S.M. (1973). Regular Polytopes. 3rd ed., Dover Pubs., New York.

Einstein, H.H., Baecher, G.B. (1981). Probabilistic and Statistical Methods in Engineering Geology: In: 30th Geomechanics Colloqium, Salzburg.

Einstein, H,.H., Baecher, G.B. (1983). Probabilistic and Statistical Methods in Engineering Geology, Specific Methods and Examples, Part I, Exploration. Rock Mechanics and Rock Engineering, 16, 39-72.

Helman, J., Hesselink, L. (1989). Representation and Display of Vector Field Topology in Fluid Flow Data Sets. IEEE Computer, 22, 27-36.

Helman, J., Hesselink, L. (1990a). Surface Representation of Two- and Three-Dimensional Fluid Flow Topology. Proc. IEEE Conf. Scientific Visualization, IEEE, Los Alamitos, in prep.

Helman, J., Hesselink, L. (1990b). In: Visualization in Scientific Computing (G. M. Nielson, ed.), videotape to accompany conference report, IEEE, Los Alamitos.

Herring, J.R. (1987). TIGRIS: Topologically Integrated Geographic Information System. AutoCarto 8, 282-291.

Jaeger, J.C., 1962, Elasticity, Fracture and Flow. 2nd ed., Methuen, London.

Mendoza, C.E. (1986). Smoothing Unit Vector Fields. J. Int. Assoc. Math. Geol., 18, 307-322.

McLaughlin, R.J. (1981). In: Research in the Geysers-Clear Lake Geothermal Area, Northern California (R. J. McLaughlin, J. Donnelly-Nolan, eds.), Geol. Surv. Prof. Pap., 1141, pp. 129-137, US Govt. Printing Office, Washington.

Muffler, L.J.P., Costain, J.K., Foley, D., Sammel, E.A., Youngquist, W. (1979).Nature and Distribution of Geothermal Energy. In: Direct Utilization of Geothermal Energy (D. N. Anderson, J. W. Lund, eds.), GRC Spec. Rept., 7, pp.1-1 to 1-15, GRC, Davis.

Requicha, A.A.G. (1980). Representations for Rigid Solids: Theory, Methods and Systems. Computing Surveys, $12,437-464$.

Turner, A.K. (1989). In: Three Dimensional Applications in Geographic Information Systems (J. Raper, ed.), Taylor \& Francis, London, pp. 115-127.

Unger, J.D., Liberty, L.M., Phillips, J.D., Wright, B.E. (1989). In: Three Dimensional Applications in Geographic Information Systems (J. Raper, ed.), Taylor \& Francis, London, pp. 137-148.

Wagner, D.L., Bortugno, E.J. (1982). Geologic Map of the Santa Rosa Quadrangle, California, 1:250,000. Regional Geologic Map Series, California Division of Mines and Geology, Sacramento.

Watson, G.S. (1985). In: Multivariate Analysis (P.R. Krishnaiah, ed.), Elsevier, Amsterdam, pp.613-625.

Weiler, K. (1985). Edge-Based Data Structures for Solid Modeling in Curved-Surface Environments. IEEE $C G \& A$, January, 21-40.

Zyvoloski, G., Dash, Z., Kelkar, S. (1988). FEHM: Finite Element Heat and Mass Transfer Code. Rpt., LA11224-MS, Los Alamos National Laboratory.

\section{DISCLAIMER}

This report was prepared as an account of work sponsored by an agency of the United States Government. Neither the United States Government nor any agency thereof, nor any of their Government. Nex any warranty, express or implied, or assumes any legal liability or responsibility for the accuracy, completeness, or usefulness of any information, apparatus, product, or process disclosed, or represents that its use would not infringe privately owned rights. Reference herein to any specific commercial product, process, or service by trade name, trademark, manufacturer, or otherwise does not necessarily constitute or imply its endorsement, recommendation, or favoring by the United States Government or any agency thereof. The views and opinions of authors expressed herein do not necessarily state or reflect those of the United States Government or any agency thereof. 